\title{
Language Maintenance among Minority Languages with Special Reference to Leya Language of Chief Mukuni, Southern Province
}

\author{
Kavwaya Sunwell \\ Copperbelt University \\ E-mail: Sunwell.kavwaya@gmail.com \\ P.O. Box 21692, Kitwe, Zambia.
}

\begin{abstract}
Minority languages die when they are competing with major languages. Major languages have a large speaker number covering a big geographical area where as minority languages are spoken by minority within a country. In Zambia, seven languages have been given official status as languages of wider Communication. These are Tonga, Nyanja, Bemba, Lozi, Luvale, Kaonde and Lunda. A research was conducted to investigate whether Tonga, the regional lingua franca and English, the nation's official language, were threatening Leya, being a minority language. The findings were that Leya language is not threatened with extinction because Leyas are proud of their language and desire to promote it. The research also showed that the Leyas preferred the use of Leya to English as a medium of instruction, do not support the use of other prestigious languages in public domains, have a positive attitude towards it so it is unlikely to die.
\end{abstract}

Keywords: Language Maintenance, Language Death, Major Languages, Minority Languages, Lingua Franca

\section{Introduction}

Language maintenance denotes the continuing use of a language in the face of competition from a regionally and socially more powerful or numerically stronger language. Leya Language is one of the minority Languages in the southern part of Zambia, which is threatened with extinction. This is because it is in the face of competition with Tonga, the regional lingua franca and English, the nation's official language. A study was conducted in Chief Mukuni of Livingstone to establish whether Leya Language was under threat of death given that it is in the face of competition from regionally and socially more powerful languages. This language has to compete for survival at two fronts: against the domination of English, the nation's official language, against the domination of Tonga, the regional lingua franca, as well as the domination of Lozi which has found its way into the Leya society because of proximity to Western Province. This possible domination by either Tonga or English is because of the nation's language policy, which recognizes English as the official national language and Tonga as the regional lingua franca. The theoretical framework governing languages in contact informed this study. As a linguistic concept, language contact refers to the presence of two or more languages in a given speech community or in an individual's repertoire resulting in both direct and indirect influence of one language on the other. In such a situation, one language may be given up completely in favor of the other or both languages may be maintained with minority changes in form of loan words from one to the other. Specifically, the study tested the theoretical position that in societies where certain local languages, which are not given such status, are more likely to be replaced by local languages rather than international languages. The study, therefore, sought to review this theoretical position and test it with primary data. Literature on language maintenance has shown that language maintenance, death and shift are overlapping terms used to describe situations in which a language ceases to be used by a speech community. This happens in a situation where a more prestigious and powerful language dominates the minority language. To highlight the overlap that exists among these terms, it is important to define them. Asher (1994) defines language maintenance as the continuing use of language in the face of competition from a regionally and socially more powerful or numerically stronger language. In language maintenance, the community collectively decides to continue using the language or languages it has traditionally used. It is the retention of a language within a community through people continuing to speak and to pass it on successive generations (Australian Social Trends, 1999). Language shift, on the other hand, refers to situations in which a language is given up completely in favor of another (Fasold, 1984) whereas language death is defined as a loss of a language without a new one replacing it. (Asher, 1994). There are a number of factors that scholars have identified as the cause of language shift or death. Asher (1994) identifies four factors associated with language death:

1. Economic factors- it is very likely that a language can shift or die when there is juxtaposition of different speech communities because of trade. 
2. Demographic factors-number of speakers does have a bearing on successful language maintenance: the smaller the size of the community, the stronger the threat of language shift and death.

3. Institutional support-if, for instance, a minority language is used in education, religion, media and administration, it can help maintain that particular language. Fang (2017) observes that institutional support makes a difference between success and failure in maintaining a minority language. He further argues that education, law and administration, religion and media are crucial domains in this regard.

4. Status- this may play a major role in language maintenance. This is demonstrated by the fact that most minority languages on the African continent have given way to other prestigious African languages rather than languages of European colonialism. This is because prestigious African languages are of higher status than minority languages. Therefore, the attitude of the speakers towards their own language plays a pivotal role in maintaining their language. Language death is in different types. However, it is important to note that these situations are not mutually exclusive and may overlap. Among these types, the following shall be discussed in some detail: sudden language death, radical language death and gradual language death. According to Dressler (1981), sudden language death involves abrupt disappearance of a language because almost all its speakers suddenly died or killed. This can also be referred to as language death by genocide. Radical language death is as 'sudden death' language loss is rapid usually due to either several political repression or genocide where speakers out of self-defense stop speaking their language. For example, in El Salvador, due to a 1932 massacre in which thousands of Indians were killed, Cacaopera and Lena soon became extinct. Many people stopped speaking their language as a survival strategy. Gradual language death is the most common. It is a loss of language due to gradual shift to the dominant language in a language contact situation. This is where the dominant language comes to be employed by a dominant number of contexts where the subordinate language was formerly used.

As regards language extinction, Asher, R. E. (Ed) (1994) argues that it is not a new phenomenon and he gives the following notable examples of languages that became extinct: Chibcha, Cornish, Egyptian and Old Prussian. This means that these languages have no living example. In other words, a language that has become extinct does not survive in its original setting. The extinction of Cornish in England in the eighteenth century is an example of language death as well as shift (to English). The demise of an immigrant language like Norwegian in the USA exemplifies shift without death since the language survives in its original setting in Norway. (Brenzinger, M. 1992). The above statement by Brenzinger underscores the demarcation line between language death and shift though the two concepts are closely related. Whereas language shift may refer to a situation, where a language shifts to another language but still survives in its original setting. Language death refers to a situation where almost the entire speakers of that language are entirely wiped out or abandoned for another. Brenzinger (1992) argues that language death without shift is exemplified by the fate of Tasmanian, whose speakers were almost wiped out just seventy-three years after the first contacts with the British settlers in 1803. He further argues that the Khoi khoi and san families of the Southern Africa have also been victims of both shift and death. Given these facts outlined above about the plight of Leya language, the question that arises is whether Leya language is under threat of death from the above-mentioned languages. This was, in fact, the problem, which was investigated to find out whether the Leya language is under threat of death given the fact that it is in the face of competition from regionally and socially more powerful languages: English, Tonga and Lozi.

The aim of the study was to investigate whether Leya, being a minority language in southern province is under threat of death.

The study sought to achieve the following objectives:

1. To establish the patterns of language use by participants within the chosen study area.

2. To establish how and why the participants acquire these languages.

3. To identify the attitude of the participants towards their own language.

4. To identify the attitude of participants towards the regional lingua franca.

While we appreciate the post-independence language policy in Zambia, which recognizes seven local languages as official languages of wider communication by province, almost nothing has been put in place to ensure that the minority languages are maintained or prevented from dying. Studies on the maintenance and future of minority languages have also been rare. The proposed study was, therefore, very important for it investigated the plight and future of Leya language which is in the face of competition with Tonga, the regional lingua franca. The study was important, too, because it provided valuable data on the effect of juxtaposition of different speech communities of minority languages. Additionally, the study sought to discover which of the two languages is likely to die- the socially more powerful and numerically stronger language or the minority language where they are competing for survival. Furthermore, the study investigated the extent to which economic and demographic factors, institutional support and status impact on language maintenance. 
Specifically, the study looked at the possibility of more prestigious languages such as Tonga and Lozi dominating the Leya speech community. It, therefore, investigated the socio-linguistic relationship between Leya on one hand and Tonga and Lozi on the other hand

\section{Methodology and Description of Study Area}

Basically, two research methods were used: qualitative and quantitative. However, the qualitative approach was employed more than the quantitative one. The qualitative approach was used to determine participants' perception of the status of the languages in question as well as their attitudes towards these languages whereas quantitative method was used to establish the extent of language use by the participants by such social variables as age, educational level, social status and others.

\subsection{Study area and sample size}

The sample for the study was drawn from Livingstone in Southern Province of Zambia to establish the socio-linguistic relationship between the local indigenous language, Leya and Tonga the regional lingua franca. A sample of 90 people was purposively selected for the study. The 90 selected participants were the indigenous Leya speakers. To ensure a fair distribution, the participants were drawn from at least three communities: Chief Mukuni's palace, Mukuni Basic School and Maramba. 30 participants were selected from each of the above-mentioned communities. These participants were then divided into subgroups in accordance with their age, social status and educational attainment. This was to determine whether age, social status and educational attainment had any impact on language maintenance.

\subsection{Sampling techniques}

Both purposive and stratified random sampling techniques were used for the study. Purposive sampling was used because the researcher was particularly interested in the information rich area- the Leya speaking community. In other words, the researcher went to this community on purpose because he thought that the individuals in this particular community fit the profile he needed to reach. This means that non-Leya speakers were not selected for the study because they did not fit this particular profile. Stratified random sampling, on the other hand, was used for dividing the sampled population into small subgroups in accordance with age social status and education attainment. This was to determine whether age, social status and educational attainment had influence on the attitude one had towards their native language.

\subsection{Data collection and instruments}

Apart from face to face interviews with the Leya speakers and the personal interview with their chief, a well-structured three-part questionnaire was used. The first part contained questions soliciting information on the participants' personal data such as age, sex occupation, tribe and level of education. The second part contained questions soliciting information on the participants' use of language in different domains such as schools, church, work, home and the like. The third and last part of the questionnaire contained questions soliciting information about the participants 'attitude towards their language and that of the regional lingua franca.The exercise of collecting data was undertaken over a period of three weeks. The researcher distributed some questionnaires to participants who showed both willingness and ability to fill them in and gave them about three - four days to carry out the task. Additionally, the researcher conducted face-to-face interviews with participants who were unable to fill the questionnaires. Their responses were then collected on questionnaires. Finally, the researcher sought an audience with Chief Mukuni, the Leya chief, and had a personal interview with him. The interview was recorded on tape.

\subsection{Data analysis}

The process of data analysis started as soon as the data had been collected. The field notes were arranged according to the main themes in relation to the objectives. Among the main objectives that the researcher sought to achieve were the following; To establish the patterns of language use among the participants within the chosen study area, to establish why and how the participants acquire these languages, to establish the participants' attitude towards their own language and to establish the extent to which Leya is being used in public domains. As regards the first objective, which looked at patterns of language use among the participants, it was observed that Leya remained dominant among people of different categories such as age, sex, occupation and level of education. This clearly shows that regardless of age, sex, occupation and level of education, the participants use Leya in interaction among them and use the other local languages in interacting with those outside their societies. Therefore, data from both the questionnaires and interviews revealed that Leya language is being maintained despite being in the face of competition with other major languages. With regard to how and why the participants acquire other languages apart from Leya, it was observed that Tonga and English are acquired at school. This is because the two languages are taught in all the schools in Livingstone. English is imposed on every child at school because of its status as the official and national language whereas Tonga is taught because of its status as a regional lingua franca despite the fact that Leya is the dominant language in Livingstone. 
The other Languages such as Lozi, Nyanja and Bemba are acquired through interactions with friends and business partners who may be speakers of these languages. The other factor which has necessitated the acquisition of these languages is trade. In order for the participants to trade with people coming from the other parts of the country, it was necessary for them to acquire Nyanja and Bemba. This is because most business transactions are done in these languages. At Maramba and Zimbabwe markets, for example, these languages seem to be dominant. Despite these social, political and economic processes that have brought about language contact between Leya and other major languages, Leya has remained resilient. It has neither died nor shifted into any of these prestigious languages. It is still largely spoken in families and other social domains. As regards the participants 'attitude towards Leya, their mother tongue, it was observed that Leya is held in the highest esteem among its speakers. Almost all the respondents indicated that they were not ashamed to speak it and they regard it as the most important language in their area. They, in fact, expressed sadness at the fact that their language is not used in some of the social domains. According to them, they would love to see a situation where Leya is taught in schools and be spoken on the national radio. They argued that it was unfair for their children to be taught in Tonga when they were not Tonga themselves. In other words, they espouse their language and they have a positive attitude towards it. As regards the extent to which Leya is used in public domain, it was observed that Leya was not very pronounced in most of the public domains despite being the indigenous language of the area. Take, for instance, the medium of instruction in schools, Tonga is used as opposed to Leya, which is the language of the locals in the area. Other public domains are domains such as the media, market, local court, political meetings and the local church. Tonga, the regional lingua franca, seems to have taken the center stage in all these domains.

\section{Results and Discussion}

\subsection{Patterns of language use}

As regards patterns of language use, it was observed that the Leya language remained dominant among people of different categories such as age, sex, occupation and level of education. This clearly shows that age, sex, occupation and level of education do not affect the maintenance of the leya language. The focus group discussions with the Leyas and the face to face interview with their chief indicated that Leya has remained the most preferred language despite the close contact with the most prestigious languages such as Tonga, Lozi, Bemba and Nyanja. Therefore, one can unequivocally argue that the acquisition of Leya among the children was facilitated by the dominance of Leya as a language of communication within the family. This clearly shows that Leya is being transmitted from one generation to another. Underlining the importance of transmission, Kishindo (1994) argued that the maintenance of a language is threatened when it is not transmitted as a first language. He partly attributed the loss of Chingoni in Malawi to the fact that acquisition as a mother tongue ceased. It is, however, important to note that 81 out of the 90 people that participated in the study revealed that they were capable of speaking more than one language. This represented ninety per cent of the sample size. In fact, the great majority showed ability and fluency in more than three languages. Perhaps, this is because of juxtaposition of various speech communities who have settled in Livingstone because of trade and tourism. Among the local languages, the respondents showed ability in the following: Leya, Tonga, Lozi, Nyanja and Bemba to a small extent. However, a few of them showed ability to speak even the English language. What this means is that participants use Leya in interacting among themselves and use the other local languages in interacting with those outside their societies. English is also used to a certain extent when they interact with foreign tourists. Among these languages mentioned above, Leya seems to be the most dominant except that it is rarely if not used in public domains. This, again, has to do with the language policy which is silent on the plight of the minority languages. Despite the absence from the public domains, Leya seems to have withstood the pressure of shifting into any of the above prestigious languages. This is principally because Leyas are consciously and actively involved in maintaining their languages. They do so by ensuring that only Leya is used in interacting among them and that it is the only language used as the language of play among their children. This seems to agree with Fang (2017) who observes that without active language maintenance shift is inevitable and without conscious maintenance minority, languages may become extinct.

\subsection{Why and how do Participants acquire other languages?}

The other languages that participants acquire apart from Leya are English, Tonga, Lozi, Nyanja and Bemba. The questionnaires and the interviews that were conducted revealed that English and Tonga are acquired at school. This is because the two languages are taught in all the schools in Livingstone. English is imposed on every child at school because of its status as the official and national language. Tonga, on the other hand, is taught as a result of its status as regional lingua franca. This is, in fact, what is enshrined in the language policy in Zambia. This language policy does not seem to protect the plight of minority languages as observed by Guo (2013) who argues that language policy is of great importance for status and protection of minority languages as well as the construction of harmonious society. 
The acquisition of these languages at school, however, has not threatened the existence of Leya. This is principally because Leya is still considered an important symbol of identity among its speakers. Guo (2013) strengthens the above argument by stating that where a language is considered an important symbol of minority group's identity, it is likely to be maintained for a long time.

The other languages such as Lozi, Nyanja, and Bemba are acquired through interaction with friends and business partners who may be speakers of these languages. The other factor, which has necessitated the acquisition of these languages, is trade. In order for the participants to trade with people coming from other parts of the country, it was necessary for them to acquire Njanja and Bemba. This is because most businesses are done in these languages. At Maramba and Zimbabwe markets, for example, these languages seem to be dominant. Mukuni village is a tourist village and tourism is the main economic activity-taking place in this village. In order for them to interact properly with the tourists who are the source of their income, they were forced to learn English.

\subsection{Participants attitude towards their own language}

One of the important factors that affect shift and maintenance of languages is attitude. (Gardner, 1985, Holmes and Harlow, 1991). Attitude refers to "a hypothetical construct used to explain the direction and persistence of human behavior" (Baker, 1992: 10). Change in language attitude is one of the major factors affecting language maintenance. With regard to attitude towards the Leya language, a set of questions were asked concerning what the respondents feel about the use of the Leya language in their community. The respondents reported a 100 per cent positive attitude towards the use of Leya in their communities. When asked whether they felt proud to use the Leya language when interacting among themselves, they reported affirmatively. Such a positive attitude goes to show that the Leya language is being maintained in the face of competition with other prestigious languages. This is consistent with Swilla, (2005) who observes that the desire for self-preservation and survival as a distinct group are among the several factors that have contributed to the maintenance of a language. Leya is held in the highest esteem among its speakers. Almost all the respondents indicated that they were not ashamed to speak it and they regard it as the most important language in their area. They, in fact, expressed sadness at the fact that their language is not used in most of the social domains. According to them, they would love to see a situation where Leya is taught in schools and is spoken on national radio. They argued that it was unfair for their children to be taught in Tonga when they were not Tonga themselves. In other words, they espouse their language and have a positive attitude towards it.

Chief Mukuni himself categorically stated that he does not subscribe to the teaching of Tonga in his chiefdom. He, however, seems to have put a stamp of approval on Tonga as opposed to Lozi which was taught in Livingstone in the past. He argues that the fact that Tonga is taught in schools instead of Lozi, is a positive step towards maintaining the Leya language. According to him, Tonga is closer to Leya than Lozi and so Leya would not be lost through the teaching of Tonga in schools.

Chief Mukuni recognizes the fact that a language can die, if among other things, its people are ashamed to speak it. He has, therefore, created a situation where every Leya speaking person wants to be associated with the Leya language. This is because of what he and others in leadership have achieved in terms of development. Among the prominent developmental project is Mukuni Development Trust. Mukuni Development Trust is "a colossal project aiming at empowering the Mukuni chiefdom communities in decision making, accessing and controlling their areas, human and natural resources so as to launch sustainable development by seeking and analyzing the communities' needs" (Kambole, 2002, Mukuni Development Trust, Article 04.0).Mukuni Development Trust has remained one of the most important weapons the Leya people are using to maintain their language. In fact, one of its aims and objectives reads: "To protect the Mukuni chiefdom language, cultures and customs as espoused by the covenants on civil and political rights in economic, social and cultural rights...." (Article 05.2.3)

Another way they are trying to maintain their language is through education. Chief Mukuni argues that a language can only die if it is a language of sweepers and guards but if it is a language of engineers, doctors, lawyers and teachers, it cannot die. This is because they will not be ashamed to speak it and that they will find even better ways of maintaining it. To this effect, a secondary school has been constructed in his chiefdom with overwhelming support from the international community. This is a school where the pupils who would have done very well at grade nine levels will be sent to do their senior secondary. These will be coming from the schools within the chiefdom. The idea is to promote education among the Leyas.

The chief recognizes the fact that it is the educated Leya that can influence the speaking of Leya on national television, the teaching of Leya in schools, the writing of the Leya orthography, dictionaries and other related literature. This is consistent with the observation by Guo (2013) who argues that a group who manage to ensure that their language is used in settings such as school or their place of worship will increase the chances of language maintenance. 
He further argues that institutional support generally makes the difference between success and failure in maintaining a minority language. Education, law and administration, religion and the media are crucial domains from this point of view. Developing the above argument further, Wu Zhengbia (2010) observes that education is an indispensable tool to maintain national cultural heritage and that it is the main channel for minority language entering into the class.

\subsection{Participants attitude towards Tonga, the regional lingua franca}

Respondents were also asked a set of questions relating to the use of Tonga in public domains and the teaching of it in schools. The general perception was that the respondents would have preferred Leya and not Tonga to be used in public domains and to be used as the language of instruction in schools.

About 18 out of 90 respondents revealed that they had no serious problem with Tonga. This represented 20 per cent of the total sample size. Their argument is that they understand Tonga very well and that they feel that Tonga is closer to Leya than any other local languages. 72 of the respondents revealed that they are not comfortable with the use of Tonga in public domains. This represented eighty percent of the sample size. They feel that Leya and not Tonga should be used in educational institutions, local newspapers and indeed on the local radio station known as Radio Mosi-o-Tunya. They further argue that not every Tonga word is accessible to Leya speakers, hence the need to have the Leya section on the national radio. In summary, it can be argued that the participants' attitude towards Tonga is good except that they would rather have Leya spoken in social and public domains. They feel that this is one way they can maintain their language and prevent it from dying.

\section{Conclusion}

The findings of this study have revealed that there is clear evidence of language maintenance among the speakers of Leya language of chief Mukuni of Kazungula and Livingstone districts. The vitality of Leya in Mukuni chiefdom of Livingstone appears to be very strong. The attitude of the Leyas towards their language, the desire to preserve their language and its cultures are the major driving forces in the maintenance of Leya that will continue for generations to come. It has been observed that both parents and children have a positive attitude towards Leya. Studies on the maintenance of local languages in Africa are important in understanding various factors that contribute to their vitality and to the relationship with other surrounding communities. Further, these studies are important for they help test theories as regards languages in contact. For instance, this particular study has shown that it is not always true that minority languages die when they are exposed to major languages. Leya has survived possible extinction because its speakers have a positive attitude towards it and have a strong desire to preserve it. In general, if minority languages are to be prevented from dying, they should be used in institutions and other public and social domains. These are institutions such as schools, judiciary and the media. Literature also plays a pivotal role where maintenance of a language is concerned. If minority languages are to survive, there must be literature written in these languages. In fact, this will help maintain the cultures of these languages. Since language is a vehicle of culture. The enlightened members of these languages should be willing to write dictionaries and grammar of these languages. Finally, speakers of minority languages should be assertive and take great pride in their language. There is no need to feel ashamed of one's own language. This will help promote and maintain these languages.

\section{References}

Asher, R.E(ed) (1994). The Encyclopedia of Language and Linguistics. Vol.4, Oxford: Pergamon press.

Australian Social Trends (1999) "Population-Population composition:”Language spoken in Australia Htt://www.abs.gov.an/Ausstats/abs@lookup/7DF24DBD70/CE508 CA25699 F005 D614.

Baker, C. (1992) Attitudes and Language. Avon: Clevendon

Brenzinger, M. (1992) "Patterns of Language Shift in East Africa. In Herbert R.K (ed) Language and Society in Africa:" The theory and Practice of Sociolinguistics. Johannesburg: Witwatersrand University Press.

Dressler, W.U. (1981). Language shift and language death- A protea challenge of the linguist, folia linguistica 15:5-27

Fang, T. (2017). "How to Maintain a Minority Language through Education." Chinese studies. 6, 1-11 https://doi.org/10.4236/chnsd.2017.61001.

Fasold, R. (1984). The Sociolinguistics of Society. Oxford: Basil Blackwell ltd.

Gardner, R.C. (19885). Social Psychology and Second Language Learning: The Role of Attitude and Motivation. London: Edward Anold. Gou, H. (2013). "Research on Language Policy and Minority Education's Fairness." Guizhon Ethinic Studies 170-173.

Holmes, J and Harlow, R. (1991). "Threads in the New Zealand Tapestry of Language." Auckland: Linguistic Society of New Zealand.

Kambole, R. P. (2002). Mukuni Development Trust. Lusaka: Registrar of Societies.

Kishindo, P. (1994). "The Impact of National Language on Minority Languages: The case of Malawi."Journal of Contemporary African Studies. 12/2: 127-50

Swilla, I.N (2005). "The Dynamics of Language Maintenance among speakers of Chindali in Mbozi District, Tanzania.” Journal of Asian and African Studies, no 70, 23-32.

Wu Zhengbia (2010)." On Important Role of Bilingual Education in inheritance and Protection of intangible cultural heritage of Ethnic Minorities.’Journal of Research on Education for Ethnic Minorities, 21, 107-111. 